\title{
Innovation and Challenges of Blockchain in Banking: A Scientometric View
}

\author{
R. Arjun, K. R. Suprabha * \\ National Institute of Technology Karnataka, Surathkal Mangalore - 575025 (India) \\ Received 30 December 2019 | Accepted 27 January 2020 | Published 28 March 2020
}

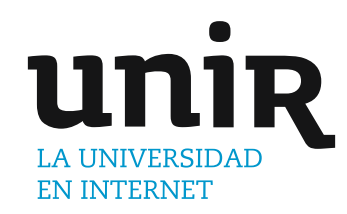

KEYWORDS

Digital Economy, Blockchain, Banking, Scientometrics, Literature Review.

: 10.9781/ijimai.2020.03.004
Blockchain has been gaining focus in research and development for diverse industries in recent years. Nevertheless, innovations that impact to the banking nurture a potential for disruptive impact globally for economic reasons; however it has received less scholarly attention. Hence the effect of blockchain technologies on banking industry is systematically reviewed. The relevant literature is extracted from Scopus, Web of Science and bibliometric techniques are applied. While a bulk of earlier papers focuses only on bit coins, a broader framework is envisaged that synthesizes interdisciplinary thematic areas for advancement; hence novelty in current work. A few practical and theoretical implications for stakeholders in view of technology, law and management are discussed. within the blockchain ecosystem for competitive advantage to banking institutions? RQ2. How will blockchain based digital platforms transform existing value-creating interactions? RQ3. What are the implications on legality, technical structure and organizations from an information systems perspective? The remaining sections of this paper are organized into Section II- background and earlier related work; Section III- methodology and data for research; Section IV- emerging research avenues; Section V- discussion \& proposed framework and Section VI- conclusion \& suggestions.

\section{RELATED WORK} is "an open, distributed ledger that can record transactions between two parties efficiently and in a verifiable and permanent way" [31]. A banking entity, traditionally an intermediary between two transacting parties; i.e. buyer and seller of financial asset, has to re-position itself in this new realm. Additionally, risk factor and impact of banking on world economy is well documented [26] [39]. Business intelligence approaches for banking have positive results [30], but IT adoption requires customization for multicultural settings [38]. The digital economy perspective demands sector analysis [6] [34], providing inclusive solutions [32]. Nevertheless, severe dearth of knowledge exists because lack of proper theoretical foundation.

Having demonstrated the impact in finance, technology and government space, the blockchain framework has extended beyond bit coin [64] [65]. A crucial question arises on ways to overcome misconceptions and identify technology caveats for developing world. By such, thin boundaries of hype and reality on blockchain applications get delineated as argued by [53]. Hence, the present study poses 3 empirical research questions: RQ1. Which are the current technologies

* Corresponding author.

E-mail addresses: arjrs123@gmail.com (R. Arjun), suprabha.kr@ gmail.com (K. R. Suprabha).
Basically the systematic review looks on the blockchain research from three lenses. First type were papers focusing exclusively on solutions to banking industry. These include theoretical models or empirical framework with potential for strategic change [3], operational advantages [25], or stock market functions. Second are which highlight practical scope or challenges in platforms, legal, technical and organizational dimensions [7] [24]. Third, specific application oriented papers utilizing conceptual/experimental settings. For core banking based solutions, works on Know-Your-Customer (KYC) [47], bank credit and financing [68], inter-bank payments [43] were explored. For stock market related, lots of innovation is missing. In stock trading business, settlement and clearing process usually consume up to three days (or longer, depending on country and bank types). This implies actual money and shares are frozen for a specific amount of time period. Such delay incurs overhead costs and businesses loss while effects is compounded in high frequency trading scenarios. Major researches have investigated market prediction models [40] [41], decentralization [29] [57], booking registrations [46], etc. Similarly, smart contract is a computer code built into the blockchain to facilitate, verify, or negotiate a contract agreement [21]. Smart contracts operate under a set of pre-set conditions that users agree to. When conditions are met, terms of the agreement are automatically executed, as for insurance [17], etc. Recent works show that open blockchain frameworks like 
IBM Fabric process transactions have higher workloads \& security than conventional databases [2].

For integrating lessons from banks [27], finance [36], strategy [70], mobile bank [10] and socio-economics [54], the current study use an exploratory approach and inductive reasoning.

\section{Methodology AND DATA}

The journal/book articles in Scopus, Web of Science and ACM, IEEE and AIS (Association for Information Systems) conference proceedings published in 2008-2019 (11 years) were collected. Additionally the patents [18], doctoral thesis [56] and industry reports [43] were used as secondary information. Under each category, the articles were chosen for their match with the theme of blockchain and industry focused. In current work, VOSviewer, an open source software tool is used for data analysis and visualization. Specifically methods used to generate the charts are BCAD (Bibliographic Coupling Analysis of Documents) and CCAR (Co-Citation Analysis of References) [66]. Specific aim is to quantitatively assess the research output in peer reviewed journals. From Scopus, 70 documents were retrieved. The Scopus data in CSV file format got downloaded to apply the bibliographic analysis method using VOSviewer software.

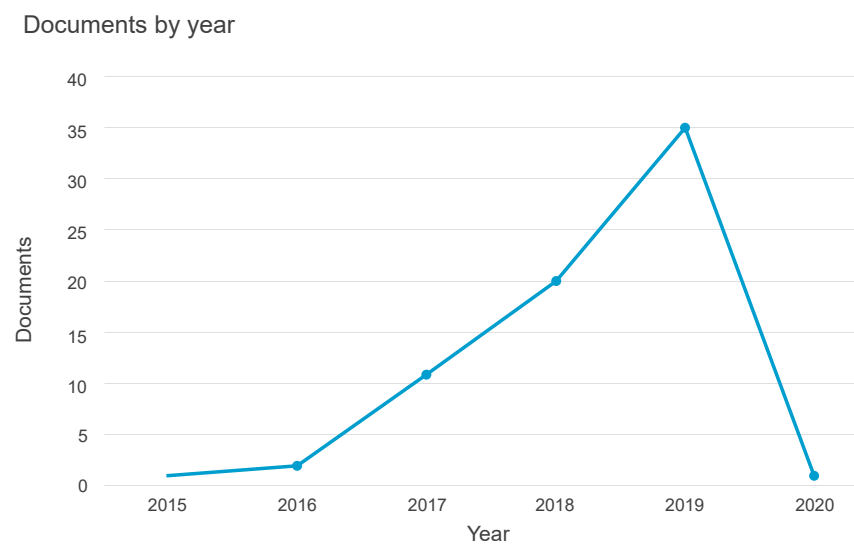

Fig. 1. Research trend (source: Scopus).

Scopus query format: (TITLE-ABS-KEY (blockchain) AND TITLEABS KEY (*bank)) AND (LIMIT-TO (SRCTYPE, "j")).

This query in database selects research articles having title, abstract or keywords as "blockchain" and "bank". Articles with 1 citation and published during 2008-2019 were used. Fig. 1 shows renewed research interest in blockchain. Only less than 5 articles were published in 2015 but by 2019 , no. increased to 35 ( $85 \%$ increase).

Documents by subject area

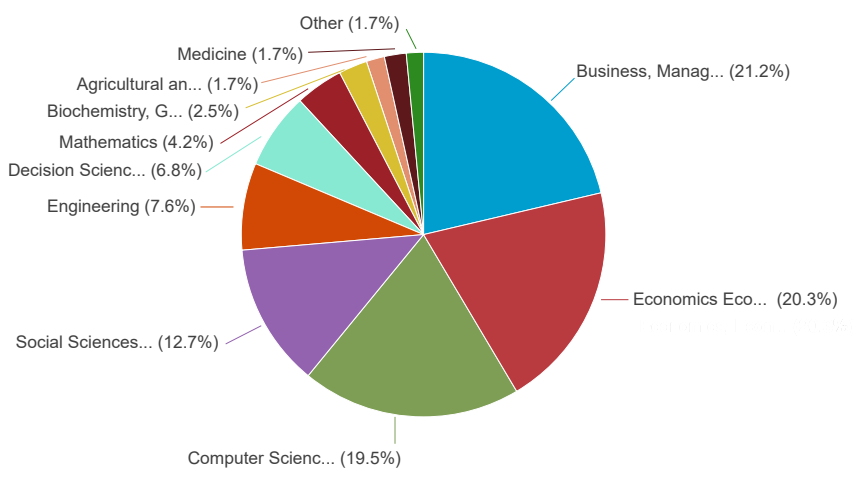

Fig. 2. Fields of research (source: Scopus).
As seen in Fig. 2, the majority of research studies constituted from Business \& Management (21.2\%), followed by Economics and related fields (20.3\%), Computer science (19.5\%) \& Social sciences $(12.7 \%)$.

Other areas contributed low to research efforts. Interestingly blockchain applications also find use in biochemistry $(2.5 \%)$, agriculture and medicine (1.7\% each) and others [61].

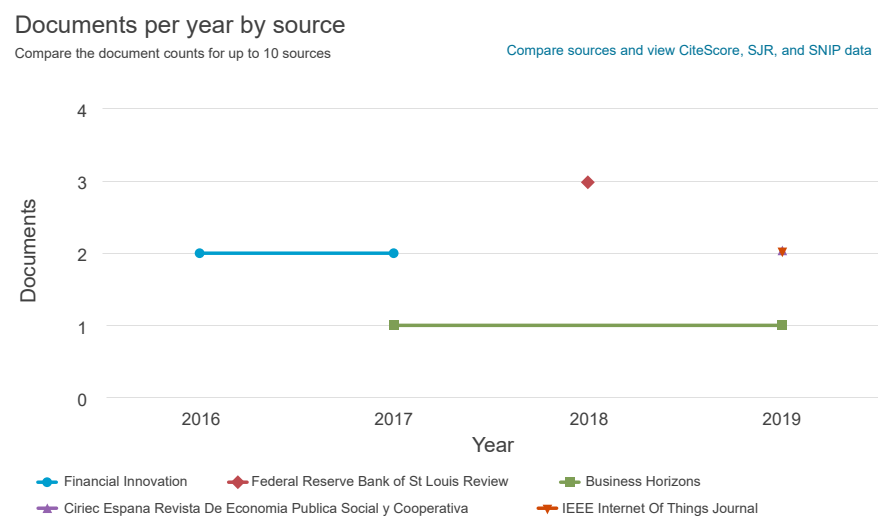

Fig. 3. Publication outlets (source: Scopus).

Fig. 3 shows the major publication peer reviewed journals that encourage blockchain research. Financial innovation has articles from 2016 to present, followed by Federal Reserve Bank of St. Louis, Business horizons and IEEE.

CCAR (Co-Citation Analysis of References): CCAR method is forward looking assessment of past works. Here the frequency of citation received for two published articles together by another paper gets counted. This method analyzes from past research perspective to highlight an intellectual foundation i.e., references highly co-cited, recognizing seminal studies for field.

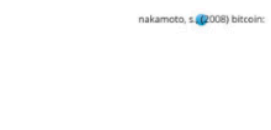

A vosviewer

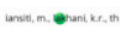

Fig. 4. CCAR output (source: VOSviewer).

As in Fig. 4, all studies were processed to visualize cited articles. The methodical assumption is that results support/contradict a particular thought school and evolve overtime. Here Nakamoto (2008) [48] appeared twice in visualization since this article is not a formally published study but rather a proof-of-concept. The other influential articles were published in 2017 [31] by HBR and an IEEE IoT study [12]. Study [31] used non-expert language to outline technical foundations of blockchain. They dispel the hype by highlighting pros and cons of blockchain systems. [12] designed framework enabling operation of blockchain + IoT devices. To find the studies on banking with stock market impact, a second search is done after varying the parameters.

BCAD (Bibliographic Coupling Analysis of Documents): This method helps in recognizing present trend/direction of research efforts. Here the measure of similarity is found among studies. This is done by identifying common references between two distinct research works. 
Basically, the procedure selects any research article having title, abstract or keywords as "blockchain" logical AND "bank" or "stock market" terms. From this, around 217 results were retrieved. Out of this, studies cited at least 1 are chosen by setting threshold value. Following this, 85 items were filtered. Out of this, 52 journal items are grouped into 8 clusters by VOSviewer (Fig. 5).

Scopus query syntax: (TITLE-ABS-KEY (blockchain) AND TITLE$A B S-K E Y$ ("stock market”) OR TITLE-ABS-KEY (bank))

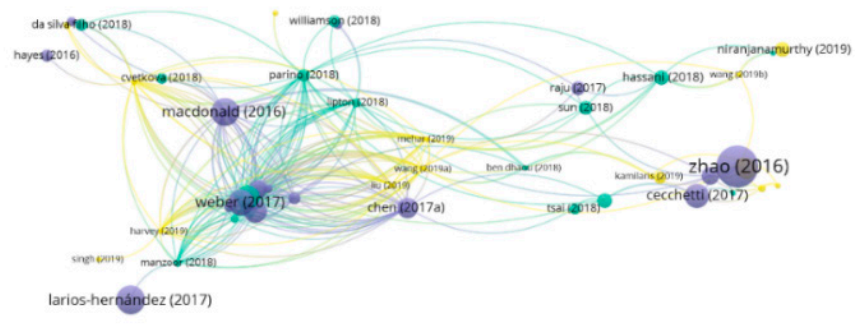

A vosviewer

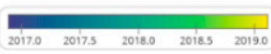

Fig. 5. BCAD output (source: VOSviewer).

The major studies are summarized in Table I in Appendix. The top Scopus paper [25] had prominence percentile score of 99.945, Field weighted citation impact 9.51 (Elsevier based metrics data).

Web of Science Analysis: Before executing WoS database query, under the databases dropdown select options, "Web of Science core collection" is chosen. After this process, 28 results are obtained, from which 22 are articles, 4 review papers, 2 book chapters and editorial material and 1 proceedings paper. From these, articles with 1 citation are chosen. After this, 17 items were visualized into 4 clusters (Fig. 6). Some of the research works that already appeared in Scopus were omitted to avoid duplication.

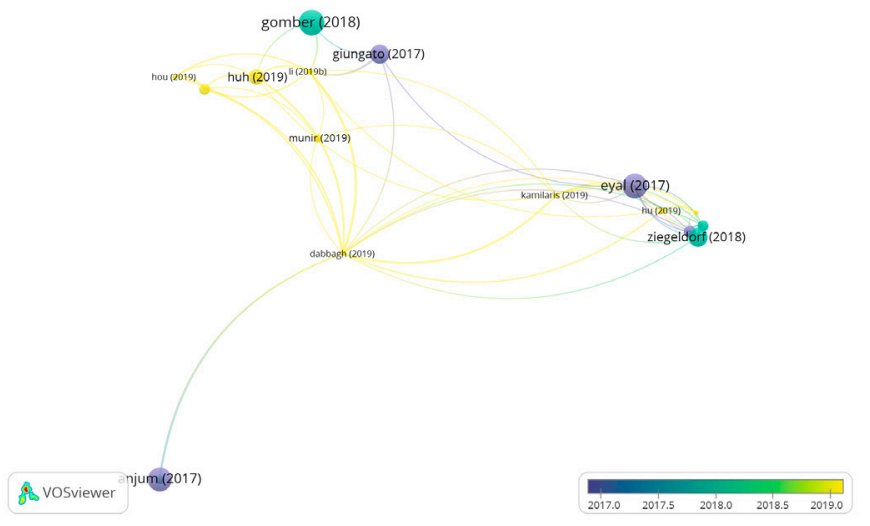

Fig. 6. BCAD output (source: VOSviewer).

Query structure: TOPIC: (blockchain) AND TOPIC: (bank) Timespan: All years. Indexes: SCI-EXPANDED.

WoS articles were not analyzed in-depth in the current study as earlier works explored the same [14]. Other works had looked to financial technology (Fintech) comprising services as well [44].

Citation Analysis: Fig. 7 shows the citation analysis of research published in Web of Science. Here the output from 89 records for Total Citing Articles without self-citations are given. It is interesting that citation trend had least quantum of links by materials science and medicinal fields. A few studies and industry reports indicate that manufacturing industry sector lacks significant advances of blockchain where operations research has disruptive potential [4].
Query structure: TOPIC: (blockchain) AND TOPIC: (bank) is visualized under the Results Analysis page of WoS database interface.
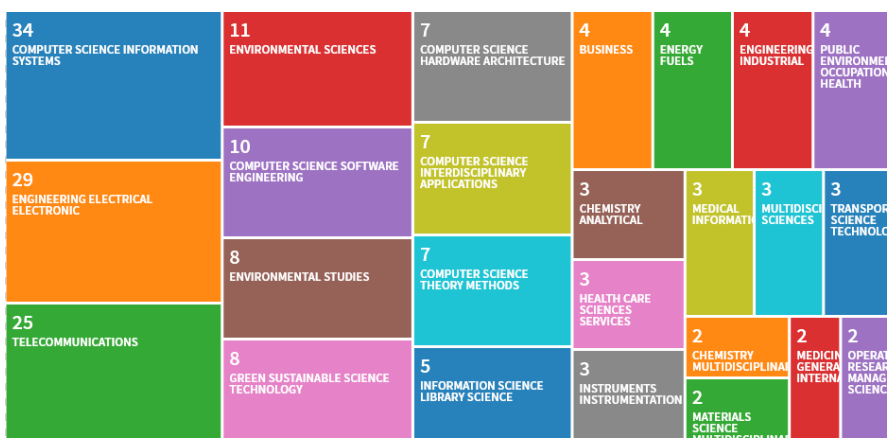

Fig. 7. Citation analysis (source: WoS).

Table II in Appendix lists the major works. Top WoS study [23] had average citations/year 9.33 as of Jan-2020 (Clarivate Analytics data).

\section{EMERging Areas of Research}

From review, the major themes are banking, information systems, innovation, law, finance [63], sustainability, entrepreneurship \& digital infrastructure (standards, scalability [72], security, \& privacy [67]). This section further examines the current directions like:

Social media leveraged prediction: Interesting research directions are: What are prediction methods to forecast future market conditions utilizing unstructured data sources? Research groups globally have increased attention to capture user generated content (UGC), social media for advanced explanatory/predictive models [56] [59].

Business model transformations: Future research questions of interest can be: What are the innovative business models that combine platform based technologies and incentivized interactions? With empirical evidence of positive correlation between bit coin transaction volume and human development, if technology solutions affect Human Development Index (HDI) in developing economies, this leads to sustainable outcomes [58] [18].

Machine learning based service evolution: Future research can investigate areas like: How do machine learning models fit into the ethical or legal framework of blockchain system? Ex: Can government/ industry body inherently frame legal implications of data privacy/ security (GDPR) and similar data protection rules into secured blockchain? Findings from these ideas can pave way for solutions to ethics, machine learning, and security researcher's community [62].

Market reaction for blockchain: Looks variations in investor reaction on short-term and long-term basis for information disclosure of bit coin prices by firms. Study compared results with SEC (Securities and Exchange Council), USA concerns and local media reports. Future research could investigate if managers exploit this momentary investor overreaction, sell stock, engaging insider trading activities, exercising options, etc. [11].

Digital platforms as infrastructure: An editorial note [13] points interesting avenues of research study that simplify intellectual property rights (IPR) to create ownership, protect rights using technologies like blockchains. Fostering the debate to balance the goals of privacy against the desire for economic growth is needed. Will social media be viewed as "critical infrastructure" given their ability to influence critical societal functions even as elections? If so, what are appropriate regulatory regimes? Which is the suitable role for government intervention into how platforms operate? Is self-regulation in digital platforms feasible? Ex. Libra from Facebook proposed as blockchain based open source digital currency. 


\section{Discussion and Proposed FrameWork}

Broadly, the issues associated in blockchain technologies specific to banking were identified. Major drawbacks of blockchain or crypto currencies are technology cost incurred, low transaction throughput, illegal use like terrorism, drug trade, cyber-crimes, etc. [20]. Therefore, need arises for industry consensus to solve challenges with collective benefit [60].

Regulatory landscape: The legality of blockchain and bit coin is subject of intense public confusion and government scrutiny, hence still a grey area. Adding to complexity, there exists ambiguity at multiple countries [33]. For example, in India, where services including banking contribute more than 50\% GDP (2018), it was announced in 2018 that bit coin was not a legal tender for transactions, but blockchain technology is promoted in payment systems.

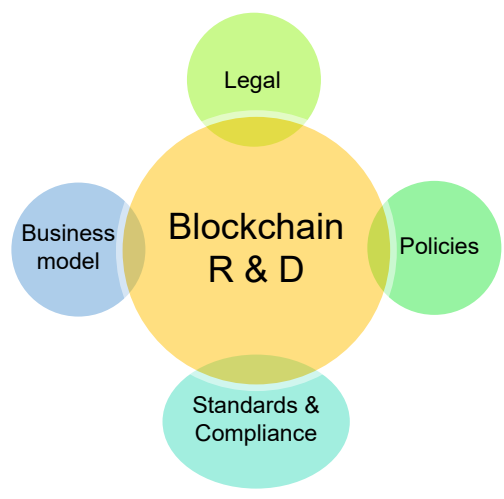

Fig. 8. Blueprint for Blockchain R\&D.

Fig. 8 depicts the conceptual map of regulatory aspects surrounding blockchain. As seen in previous ex: the logical connective in legal-economic policy-compliance and business model emerges as paramount [45]. Extent of controls, under/over regulation, policies in turn affect the ecosystem. The ambit of policies must be delineated in $\mathrm{R} \& \mathrm{D}$ and practice by a modular approach.

Infrastructure requirements: Whenever scope exists for security, privacy, technical capability, organizations in blockchain ecosystem must assess their SWOT [50]. This process can foster better Human Computer Interaction (HCI) modules [16]. Coordinating these well helps investor's perspective of solution of business model. Fig. 9 depicts hierarchy required by generic business/non-profit organizations venturing in blockchain.

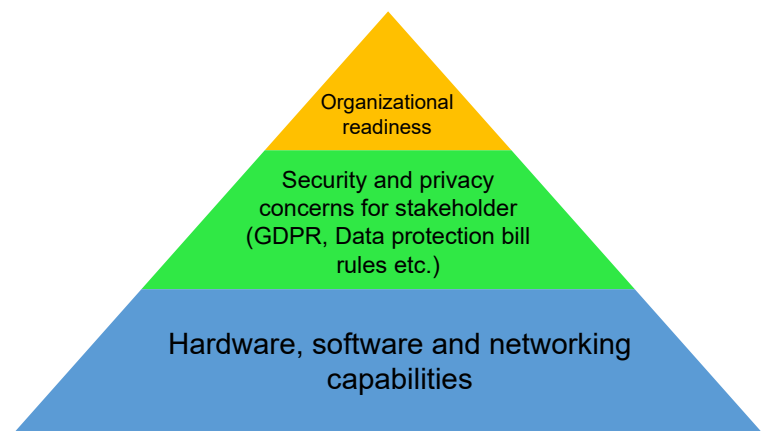

Fig. 9. Requirements hirearchy.

Socio-economic drivers: The blockchain ecosystem, like any other major technological up gradation or shifting, requires a multilevel effort and time. The process of technology use and adoption of literature and models, such as TAM (Technology Acceptance Model)/UTAT (Unified
Theory of Acceptance and Use of Technology), and status quo theory finds relevance in this context [9].

Another interesting study analyzed the changes brought by bit coin from bank currency notes even culturally [24]. The framework attempts in coherent logic linking theories from information systems, management and sociology.

Effect of bit coin prices and impact of alternate bank systems in economy policy had been investigated earlier [15] [35] [52] denoting economic impact. Fig. 10 outlines a roadmap to develop blockchain systems in cross-country basis. It synthesizes earlier work [54], to map concerns [19], pitfalls of regulation, technical/organization aspects.

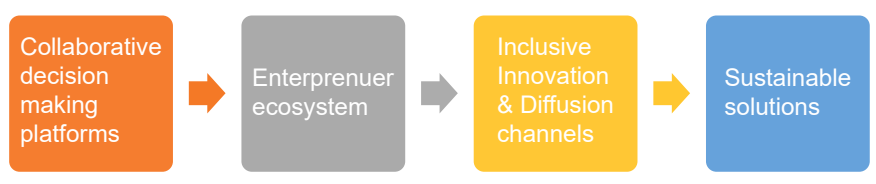

Fig. 10. Socio-economic factors.

\section{CONCLUSION}

One limitation of this study is that only 72 research works could be covered in the systematic review. The external databases (JSTOR etc.) hold more literature but is outside the scope of this paper. Also, citation data from Scopus/WoS compared to Google Scholar or reference managers like Mendeley, etc. varies highly. Hence the criteria to choose research is only judgmental; for ex: citations count as proxy measure for impact. While earlier works limited to WoS, present study overcomes with Scopus also. There are two papers visually located far from clusters centroids, indicating lack of extended work on entrepreneurship and standards that hinders blockchain [37] [1]. Also, general inference is that blockchain technology is affected by government, infrastructure and organizational dynamics. While Scopus has literature addressing specific applications and empirical practice, WoS offers insights into the theoretical dimensions and societal implication aspects.

Now answering the posed questions, RQ1: In developing economies, consortium led blockchain systems like R3 and strategizing of Fintech 2.0 roadmap are essential. Instead of replicating strategies of firms like Google, Amazon, Apple or Facebook, etc. the digital banking systems must be redesigned for newer modalities. One such example is Paytm of India. Most of these firms are developing in-house payments ex: Apple Pay, Google Pay enabled with near field technologies (NFC), contactless payments or facial recognitions. Hence, a paradigm shift to evolve banking models on services and operations front is key to stay relevant. RQ2 answer: Synergy of banking management information systems with worldwide real-time inter-bank network is the future. By monitoring global risks, functionality is augmented using interactive and business intelligence tools for mobile banking, stock market predictions, credit evaluations, risk management, etc. for investors and customers. Banking-as-a-service (BaaS) has evolved into service platform impacting the customer-businesses-government interactions. RQ3 answer: The standardization in transactions, privacy/ security infrastructure and resolution mechanism by large banking institutions can influence smaller and non-banking public and private blockchain entities. New corporate social media and customer relations management will hence be strong catalysts for operations strategy. The government, industry and stakeholder community must undertake holistic \& co-creation approach for blockchain solutions. The current paper intends as blueprint to transform concerns and formulate actionable deliverables. Future work can adopt causal research using either panel data or survey based investigation into effectiveness of blockchain solutions. 
APPENDIX

TABLE I. Top 10 Impact Making Research (Based on Citations)

\begin{tabular}{|c|c|c|c|c|}
\hline Author/Study & Objective \& Methods & Findings and limitations & Major theme and suggestions. & $\begin{array}{l}\text { Total } \\
\text { citations } \\
\text { (TC) }\end{array}$ \\
\hline $\begin{array}{l}\text { Guo and Liang } \\
(2016)[25]\end{array}$ & $\begin{array}{l}\text { To assess the blockchain for banking } \\
\text { industry in the Chinese context. Uses } \\
\text { primary data and industry reports. }\end{array}$ & $\begin{array}{l}\text { Blockchain + banks (FinTech 2.0) } \\
\text { has superior customer experience, } \\
\text { efficiency, cost and security. }\end{array}$ & $\begin{array}{l}\text { Banking. } \\
\text { Shift to R3, consortium led } \\
\text { blockchain. Payment clearing system, } \\
\text { bank credit information systems are } \\
\text { vital. }\end{array}$ & 91 \\
\hline $\begin{array}{l}\text { Zhao et al. (2016) } \\
\text { [71] }\end{array}$ & $\begin{array}{l}\text { Editorial note. Introduction to } 7 \\
\text { academic papers in special edition. }\end{array}$ & $\begin{array}{l}\text { Multidisciplinary nature of } \\
\text { blockchain research. WoS and SSRN } \\
\text { articles grown from } 0 \text { in } 2014 \text { to } 11 \\
\text { and } 79 \text { respectively by } 2016 .\end{array}$ & $\begin{array}{l}\text { Innovation. } \\
\text { Challenges remain on theoretical } \\
\text { issues of societal impact, smart } \\
\text { contracts, security etc. }\end{array}$ & 57 \\
\hline Kiviat (2015) [33] & $\begin{array}{l}\text { To integrate research from diverse } \\
\text { domains and educate legal } \\
\text { community, help practitioners. } \\
\text { Primary and secondary data, legal } \\
\text { proceedings analysis. }\end{array}$ & $\begin{array}{l}\text { Regulatory patchworks are underway } \\
\text { in USA but virtual currencies pose } \\
\text { uncertainty. }\end{array}$ & $\begin{array}{l}\text { Legal. } \\
\text { Policymaker must be cautious and } \\
\text { have precision in tailoring the scope } \\
\text { of regulation }\end{array}$ & 44 \\
\hline $\begin{array}{l}\text { Nguyen (2016) } \\
{[51]}\end{array}$ & $\begin{array}{l}\text { To study role of blockchain in } \\
\text { sustainable outcomes investigating in } \\
\text { finance industry. Secondary sources } \\
\text { and data used. }\end{array}$ & $\begin{array}{l}\text { Limits competition as blockchain } \\
\text { network will be shared. Risks from } \\
\text { payment, technology cost and } \\
\text { stability hinder. }\end{array}$ & $\begin{array}{l}\text { Sustainability. } \\
\text { Further study on crowdsourcing, } \\
\text { payment system. Banks face pressure } \\
\text { from investors and competing } \\
\text { MNC's. }\end{array}$ & 33 \\
\hline $\begin{array}{l}\text { Larios-Hernández } \\
\text { (2017) [37] }\end{array}$ & $\begin{array}{l}\text { To explain lack of formal bank } \\
\text { account. Leverage the Blockchain } \\
\text { based financial inclusion. Uses fuzzy- } \\
\text { set Qualitative Comparative Analysis } \\
\text { (fsQCA) }\end{array}$ & $\begin{array}{l}\text { Variety of supply-and demand-related } \\
\text { causal factors. } \\
\text { Informal peer-to-peer practice is } \\
\text { customary. }\end{array}$ & $\begin{array}{l}\text { Entrepreneurship/ financial } \\
\text { inclusion. } \\
\text { Business logic of existing financial } \\
\text { institutions hinder the solutions for } \\
\text { unbanked. }\end{array}$ & 27 \\
\hline $\begin{array}{l}\text { MacDonald et al. } \\
(2016)[42]\end{array}$ & $\begin{array}{l}\text { To explore the implications of } \\
\text { blockchain technology on the future } \\
\text { of banking. Uses systematic review } \\
\text { and theory building methods. }\end{array}$ & $\begin{array}{l}\text { Enables to competing banks } \\
\text { organizations, shifting banking } \\
\text { transactions to out of centralized } \\
\text { organizations and into decentralized } \\
\text { markets. }\end{array}$ & $\begin{array}{l}\text { Economy. } \\
\text { Need to find balance between } \\
\text { technology adoption and governance. }\end{array}$ & 25 \\
\hline $\begin{array}{l}\text { Weber et al. } \\
(2017)[69]\end{array}$ & $\begin{array}{l}\text { To find out limitations of two } \\
\text { mainstream blockchains, Ethereum } \\
\text { and Bit coin. Uses simulation } \\
\text { experiments. }\end{array}$ & $\begin{array}{l}\text { Network reordering impact } \\
\text { transaction commit times and } \\
\text { even counter balance the effects of } \\
\text { transaction fees and gas price. }\end{array}$ & $\begin{array}{l}\text { Distributed systems. } \\
\text { Application developers must consider } \\
\text { factors that may dramatically affect } \\
\text { quality of service. }\end{array}$ & 23 \\
\hline $\begin{array}{l}\text { Giungato et al. } \\
\text { (2017) [22] }\end{array}$ & $\begin{array}{l}\text { To define and evaluate sustainability } \\
\text { of bit coin, and environmental } \\
\text { impacts, social issues and economic } \\
\text { aspects. }\end{array}$ & $\begin{array}{l}\text { Transition of the entire monetary } \\
\text { system to a new crypto currency can } \\
\text { result in an undesirable amount of } \\
\text { energy consumed to mine new bit } \\
\text { coins. }\end{array}$ & $\begin{array}{l}\text { Sustainability. } \\
\text { Extend to medical data, energy } \\
\text { generation and distribution in micro- } \\
\text { grids at the citizen level, block-stack } \\
\& \text { state-driven crypto currencies. }\end{array}$ & 20 \\
\hline $\begin{array}{l}\text { Cecchetti et al. } \\
\text { (2017) [8] }\end{array}$ & $\begin{array}{l}\text { To design Solidus, a protocol for } \\
\text { confidential transactions on public } \\
\text { blockchains, such as those required } \\
\text { for asset transfers with on-chain } \\
\text { settlement. }\end{array}$ & $\begin{array}{l}\text { Implements Solidus and present a } \\
\text { set of benchmarks indicating that the } \\
\text { system is efficient. }\end{array}$ & $\begin{array}{l}\text { Data privacy. } \\
\text { Solidus hides transaction values and } \\
\text { transaction graph (i.e., identities } \\
\text { of transacting entities) while } \\
\text { maintaining the public verifiability. }\end{array}$ & 20 \\
\hline $\begin{array}{l}\text { Berentsen and } \\
\text { Schär (2018) [7] }\end{array}$ & $\begin{array}{l}\text { An introduction to bit coin, operation } \\
\text { and applications. }\end{array}$ & $\begin{array}{l}\text { Price volatility and scaling issues } \\
\text { makes bit coin adoption a complex } \\
\text { affair. }\end{array}$ & $\begin{array}{l}\text { Crypto currencies. } \\
\text { Bit coin and crypto assets have } \\
\text { potential to become asset class. }\end{array}$ & 18 \\
\hline
\end{tabular}


Table II. Top 5 Impact Making Research (Based on Citations)

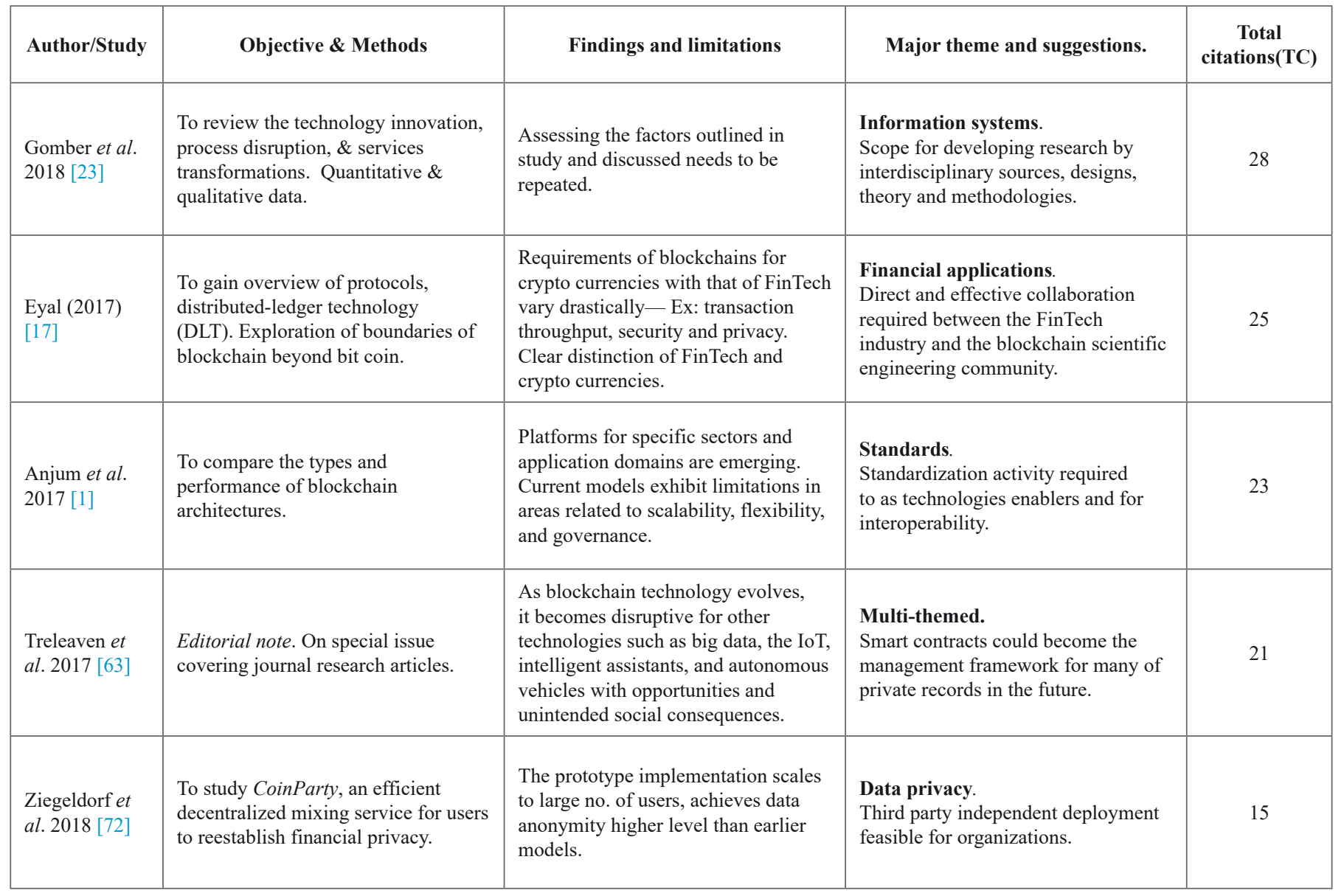

\section{ACKNOWLEDGMENT}

The first author is grateful for research scholarship support from National Institute of Technology Karnataka. Both the authors express invaluable appreciation to the reviewers, editorial team for suggesting improvements in the paper. Authors declare no conflict of interests.

\section{REFERENCES}

[1] Anjum, A., Sporny, M. and Sill, A., 2017. Blockchain standards for compliance and trust. IEEE Cloud Computing, 4(4), pp.84-90.

[2] Ankur Sharma, Felix Martin Schuhknecht, Divya Agrawal, and Jens Dittrich. 2019. Blurring the Lines between Blockchains and Database Systems: the Case of Hyperledger Fabric. In Proceedings of the 2019 International Conference on Management of Data (SIGMOD '19). ACM, 105-122. DOI: https://doi.org/10.1145/3299869.3319883

[3] Ashta, A. and Biot-Paquerot, G., 2018. Fintech evolution: Strategic value management issues in a fast changing industry. Strategic Change, 27(4), pp.301-311.

[4] Babich, V. and Hilary, G., 2019. Distributed ledgers and operations: What operations management researchers should know about blockchain technology. Manufacturing \& Service Operations Management. https:// doi.org/10.1287/msom.2018.0752

[5] Baldominos, A., Saez, Y., 2019. Coin.AI: A Proof-of-Useful-Work Scheme for Blockchain-Based Distributed Deep Learning. Entropy, 21, p.723.

[6] Benito, S., de Juan, R., Gómez, R. and Mochón, F., 2015. Differences in Measuring Market Risk in Four Subsectors of the Digital Economy. International Journal of Interactive Multimedia and Artificial Intelligence, 3(2), pp.9-16.

[7] Berentsen, A. and Schär, F., 2018. A Short Introduction to the World of Cryptocurrencies. Federal Reserve Bank of St. Louis Review, 100(1), pp.1-16.
[8] Cecchetti, E., Zhang, F., Ji, Y., Kosba, A., Juels, A. and Shi, E., 2017, October. Solidus: Confidential distributed ledger transactions via PVORM. In Proc. of 2017 ACM SIGSAC Conference on Computer and Communications Security (pp. 701-717). ACM.

[9] Chatfield, A.T. and Reddick, C., 2019. Blockchain Investment Decision Making in Central Banks: A Status Quo Bias Theory Perspective. AMCIS 2019 Proceedings. https://aisel.aisnet.org/amcis2019/digital_government/ digital_government/3/

[10] Chen, Z., Li, Y., Wu, Y. and Luo, J., 2017. The transition from traditional banking to mobile internet finance: an organizational innovation perspective-a comparative study of Citibank and ICBC. Financial Innovation, 3(1), p.12.

[11] Cheng, S.F., De Franco, G., Jiang, H. and Lin, P., 2019. Riding the Blockchain Mania: Public Firms' Speculative 8-K Disclosures. Management Science https://doi.org/10.1287/mnsc.2019.3357

[12] Christidis, K. and Devetsikiotis, M., 2016. Blockchains and smart contracts for the internet of things. IEEE Access, 4, pp. 2292-2303.

[13] Constantinides, P., Henfridsson, O. and Parker, G.G., 2018. IntroductionPlatforms and Infrastructures in the Digital Age. Information Systems Research, 29(2), pp.381-400.

[14] Dabbagh, M., Sookhak, M. and Safa, N.S., 2019. The evolution of blockchain: A bibliometric study. IEEE Access, 7, pp.19212-19221.

[15] Dwyer, G.P., 2015. The economics of Bit coin and similar private digital currencies. Journal of Financial Stability, 17, pp.81-91.

[16] Elsden, C., Manohar, A., Briggs, J., Harding, M., Speed, C. and Vines, J., 2018. Making sense of blockchain applications: A typology for HCI. In Proc. of the 2018 CHI Conference on Human Factors in Computing Systems (p. 458). ACM.

[17] Eyal, I., 2017. Blockchain technology: Transforming libertarian cryptocurrency dreams to finance and banking realities. Computer, 50(9), pp.38-49.

[18] Fay, T. and Paniscotti, D., Nasdaq Inc, 2016. Systems and methods of blockchain transaction recordation. U.S. Patent Application 15/086,801. 
[19] Fernandez-Vazquez, S., Rosillo, R., De La Fuente, D. and Priore, P., 2019. Blockchain in FinTech: A mapping study. Sustainability, 11(22), p.6366.

[20] Foley, S., Karlsen, J.R. and Putniņ̌š, T.J., 2019. Sex, drugs, and bit coin: How much illegal activity is financed through cryptocurrencies?. The Review of Financial Studies, 32(5), pp.1798-1853.

[21] Gatteschi, V., Lamberti, F., Demartini, C., Pranteda, C. and Santamaría, V., 2018. Blockchain and smart contracts for insurance: Is the technology mature enough?. Future Internet, 10(2), p.20.

[22] Giungato, P., Rana, R., Tarabella, A. and Tricase, C., 2017. Current trends in sustainability of bit coins and related blockchain technology. Sustainability, 9(12), p.2214.

[23] Gomber, P., Kauffman, R.J., Parker, C. and Weber, B.W., 2018. On the fintech revolution: interpreting the forces of innovation, disruption, and transformation in financial services. Journal of Management Information Systems, 35(1), pp.220-265.

[24] Grossman, J.H., 2019. Passing cash from bank notes to bit coin: standardizing money. Journal of Cultural Economy, 12(4), pp.299-316.

[25] Guo, Y. and Liang, C., 2016. Blockchain application and outlook in the banking industry. Financial Innovation, 2(1), p.24.

[26] Haldane, A.G. and May, R.M., 2011. Systemic risk in banking ecosystems. Nature, 469(7330), p.351. https://doi.org/10.1038/nature09659

[27] Harris, W. and Wonglimpiyarat, J., 2019, Blockchain platform and future bank competition, Foresight. https://doi.org/10.1108/FS-12-2018-0113

[28] Hassani, H., Huang, X. and Silva, E., 2018. Banking with blockchain-ed big data. Journal of Management Analytics, 5(4), pp.256-275.

[29] Hayes, A., 2016. Decentralized banking: monetary technocracy in the digital age. In Banking Beyond Banks and Money (pp. 121-131). Springer, Cham.

[30] Hu, D., Zhao, J.L., Hua, Z. and Wong, M., 2012. Network-Based Modeling and Analysis of Systemic Risk in Banking Systems. MIS Quarterly, 36(4).

[31] Iansiti, M. and Lakhani, K.R., 2017. The truth about blockchain. Harvard Business Review, 95(1), pp.118-127.

[32] Kehr, H., Tonkin, G. and Bihler, R., 2017. The Unbanked Don't Need More Brick and Mortar Banks. In Shaping the Digital Enterprise (pp. 139156). Springer, Cham.

[33] Kiviat, T.I., 2015. Beyond bit coin: Issues in regulating blockchain transactions. Duke LJ, 65, p.569.

[34] Kou, G., Chao, X., Peng, Y., Alsaadi, F.E. and Herrera-Viedma, E., 2019. Machine learning methods for systemic risk analysis in financial sectors. Technological and Economic Development of Economy, pp.1-27.

[35] Krainer, R.E., 2017. Economic stability under alternative banking systems: Theory and policy. Journal of Financial Stability, 31, pp.107-118.

[36] Kruglova, I.A. and Dolbezhkin, V.A., Objective Barriers to the Implementation of Blockchain Technology in the Financial Sector. In 2018 International Conference on Artificial Intelligence Applications and Innovations (IC-AIAI) (pp. 47-50). IEEE.

[37] Larios-Hernández, G.J., 2017. Blockchain entrepreneurship opportunity in the practices of the unbanked. Business Horizons, 60(6), pp.865-874.

[38] Leonardi, P.M., Bailey, D.E., Diniz, E.H., Sholler, D. and Nardi, B.A., 2016. Multiplex Appropriation in Complex Systems Implementation: The Case of Brazil's Correspondent Banking System. MIS Quarterly, 40(2), pp.461-473.

[39] Lipton, A., 2018. Blockchains and distributed ledgers in retrospective and perspective. The Journal of Risk Finance, 19(1), pp. 4-25.

[40] Liu, X. and Lin, N., 2018. An Automatic Discovery Process of Stock Value Information with Software Industry Based on Blockchain. In 2018 IEEE 9th International Conference on Software Engineering and Service Science (ICSESS) (pp. 136-139). IEEE.

[41] Liu, X. and Yu, T., 2018. An automatic pattern recognition value system with listed banks based on blockchain. In 2018 IEEE 3rd Advanced Information Technology, Electronic and Automation Control Conference (IAEAC) (pp. 1850-1854).

[42] MacDonald, T.J., Allen, D.W. and Potts, J., 2016. Blockchains and the boundaries of self-organized economies: Predictions for the future of banking. In Banking beyond banks and money (pp. 279-296). Springer, Cham. https://doi.org/10.1007/978-3-319-42448-4_14

[43] Meszaros, R., Adachi, D., Dharamsi, H., Yetiskin, B., \& Thomas, P. (2016). Blockchain Technology: How banks are building a real-time global payment network. Accenture Mobility. https://www.accenture. com/ acnmedia/pdf-35/accenture-blockchain-how-banks-building-real- time-global-payment-network.pdf Accessed on 18-11-2019

[44] Milian, E.Z., Spinola, M.D.M. and de Carvalho, M.M., 2019. Fintechs: A literature review and research agenda. Electronic Commerce Research and Applications, 34, p.100833.

[45] Mik, E., 2017. Smart contracts: terminology, technical limitations and real world complexity. Law, Innovation and Technology, 9(2), pp.269-300.

[46] Miraz, M.H. and Donald, D.C., 2018. Application of Blockchain in Booking and Registration Systems of Securities Exchanges. In 2018 International Conference on Computing, Electronics \& Communications Engineering (iCCECE) (pp. 35-40). IEEE.

[47] Moyano, J.P. and Ross, O., 2017. KYC optimization using distributed ledger technology. Business \& Information Systems Engineering, 59(6), pp.411-423.

[48] Nakamoto, S. Bit coin: A Peer-to-Peer Electronic Cash System. 2008. Available online: https://bit coin.org/bit coin.pdf Accessed on 30-09-2019.

[49] Narayanan, A. and Clark, J., 2017. Bit coin's academic pedigree. Communications of the ACM, 60(12), pp.36-45.

[50] Niranjanamurthy, M., Nithya, B.N. and Jagannatha, S., 2018. Analysis of Blockchain technology: pros, cons and SWOT. Cluster Computing, pp.115.

[51] Nguyen, Q.K., 2016. Blockchain-a financial technology for future sustainable development. In 2016 3rd International Conference on Green Technology and Sustainable Development (GTSD) (pp. 51-54). IEEE.

[52] Othman, A.H.A., Alhabshi, S.M., Kassim, S. and Sharofiddin, A., 2019. The impact of cryptocurrencies market development on banks' deposits variability in the GCC region. Journal of Financial Economic Policy. https://doi.org/10.1108/JFEP-02-2019-0036

[53] Peck, M.E., 2017. Blockchain world-Do you need a blockchain? This chart will tell you if the technology can solve your problem. IEEE Spectrum, 54(10), pp.38-60.

[54] Parino, F., Beiró, M.G. and Gauvin, L., 2018. Analysis of the Bit coin blockchain: socio-economic factors behind the adoption. EPJ Data Science, 7(1), p.38.

[55] Peters, G.W. and Panayi, E., 2016. Understanding modern banking ledgers through blockchain technologies: Future of transaction processing and smart contracts on the internet of money. In Banking beyond banks and money (pp. 239-278). Springer, Cham.

[56] Phillips, R.C., 2019. The Predictive Power of Social Media within Cryptocurrency Markets (Doctoral dissertation, UCL (University College London). https://discovery.ucl.ac.uk/id/eprint/10071683/

[57] Pop, C., Pop, C., Marcel, A., Vesa, A., Petrican, T., Cioara, T., Anghel, I. and Salomie, I., 2018. Decentralizing the stock exchange using blockchain an ethereum-based implementation of the Bucharest Stock Exchange. In 2018 IEEE 14th International Conf. on Intelligent Computer Communication and Processing (ICCP) (pp. 459-66).

[58] Qureshi, S. and Xiong, J., 2019. The effect of Bit coin Transactions on Human Development: Emerging Business Models. 25th Americas Conference on Information Systems, Cancun.https://aisel.aisnet.org/ amcis2019/global_dev/global_dev/10/

[59] Rousidis, D., Koukaras, P. and Tjortjis, C., 2019. Social media prediction: a literature review. Multimedia Tools and Applications, pp.1-33. https:// doi.org/10.1007/s11042-019-08291-9

[60] Salman, T., Jain, R. and Gupta, L., 2018. Probabilistic Blockchains: A Blockchain Paradigm for Collaborative Decision-Making. In 2018 9th IEEE Annual Ubiquitous Computing, Electronics \& Mobile Communication Conference (UEMCON) (pp. 457-465)

[61] Smetana, S., Seebold, C. and Heinz, V., 2018. Neural network, blockchain, and modular complex system: The evolution of cyber-physical systems for material flow analysis and life cycle assessment. Resources, Conservation and Recycling, 133, pp.229-230.

[62] Sun Yin, H.H., Langenheldt, K., Harlev, M., Mukkamala, R.R. and Vatrapu, R., 2019. Regulating cryptocurrencies: a supervised machine learning approach to de-anonymizing the bit coin blockchain. Journal of Management Information Systems, 36(1), pp.37-73.

[63] Treleaven, P., Brown, R.G. and Yang, D., 2017. Blockchain technology in finance. Computer, 50(9), pp.14-17.

[64] Tschorsch, F. and Scheuermann, B., 2016. Bit coin and beyond: A technical survey on decentralized digital currencies. IEEE Communications Surveys \& Tutorials, 18(3), pp.2084-2123.

[65] Underwood, S., 2016. Blockchain beyond bit coin. Communications of the 
ACM, 59(11), pp.15-17.

[66] Van Eck, N. and Waltman, L., 2009. Software survey: VOSviewer, a computer program for bibliometric mapping. Scientometrics, 84(2), pp.523-538.

[67] Wang, H., Ma, S., Dai, H.N., Imran, M. and Wang, T., 2019. Blockchainbased data privacy management with nudge theory in open banking. Future Generation Computer Systems. https://doi.org/10.1016/j. future.2019.09.010

[68] Wang, R., Lin, Z. and Luo, H., 2019. Blockchain, bank credit and SME financing. Quality \& Quantity, 53(3), pp.1127-40.

[69] Weber, I., Gramoli, V., Ponomarev, A., Staples, M., Holz, R., Tran, A.B. and Rimba, P., 2017. On availability for blockchain-based systems. In 2017 IEEE 36th Symposium on Reliable Distributed Systems (SRDS) (pp. 64-73). IEEE.

[70] Woodside, J.M., Augustine Jr, F.K. and Giberson, W., 2017. Blockchain technology adoption status and strategies. Journal of International Technology and Information Management, 26(2), pp.65-93.

[71] Zhao, J.L., Fan, S. and Yan, J., 2016. Overview of business innovations and research opportunities in blockchain and introduction to the special issue. Financial Innovation, 2(1), pp.1-7.

[72] Ziegeldorf, J.H., Matzutt, R., Henze, M., Grossmann, F. and Wehrle, K., 2018. Secure and anonymous decentralized Bit coin mixing. Future Generation Computer Systems, 80, pp.448-466.

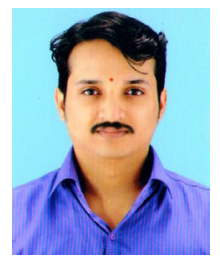

Arjun R

Arjun $\mathrm{R}$ is a doctoral scholar specialized in Information systems at National Institute of Technology Karnataka, India. He has Masters in Software Engineering from Cochin University of Science \& Technology. Research interests are Information Systems \& Cybernetics. He has published research in international journals and reputed conferences.

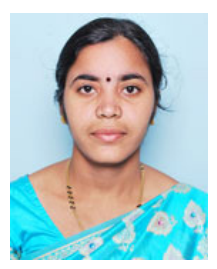

Suprabha K.R

Dr. Suprabha K.R is an Assistant Professor at the NIT Karnataka, India. She has obtained PhD from VTU, India. She has guided research scholars and published in reputed journals and conferences while winning best paper awards. She is an investigator for funded research projects. 